\title{
Evolution, Control, and Effects of Interface in CNT/Al Composites: a Review
}

\author{
Genlian Fan $\cdot$ Ziyun Yu $\cdot$ Zhanqiu Tan $\cdot$ Zhiqiang Li $\cdot$ Di Zhang
}

Received: 17 June 2014/Revised: 10 August 2014/Published online: 13 September 2014

(C) The Chinese Society for Metals and Springer-Verlag Berlin Heidelberg 2014

\begin{abstract}
This review summarizes the work carried out in the field of interface study in carbon nanotube reinforced aluminum (CNT/Al) composites. Much research work has been conducted to reveal the evolution of CNT/Al interface in producing the composite with the purpose of achieving uniform distribution of CNTs and tight interfacial bonding. The effect and principles of coating were reviewed along with the illustration of "intermetallic interphases" design. Different roles of CNT/Al interface in structural and functional application were elucidated, and the future work that needs attention was addressed.
\end{abstract}

\section{KEY WORDS: CNT/Al composites; Interface evolution; Interface control; Coating}

\section{Introduction}

Metal matrix composites (MMCs) show great potential for their applications in transportation, aerospace, and national defense. The addition of reinforcements introduces some outstanding mechanical and functional properties into the metal matrix and the characteristics of interface between reinforcements and matrix substantially affect the performance of materials. Among all the MMCs, carbon nanotube reinforced aluminum $(\mathrm{CNT} / \mathrm{Al})$ composite is a promising one due to its high specific strength and stiffness combined with light weight [1]. However, property of present CNT/Al composites is far from expectation due to the lack of appropriate interface control and design. Compared with traditional reinforcements of micrometer size, the nano-sized CNTs introduce larger volume fraction of interface in CNT/Al composites, which makes the effect

Available online at http://link.springer.com/journal/40195

G. Fan $\cdot$ Z. Yu $\cdot$ Z. Tan $\cdot$ Z. Li $\cdot$ D. Zhang $(\bowtie)$

State Key Laboratory of Metal Matrix Composites, Shanghai Jiao Tong University, Shanghai 200240, China

e-mail: zhangdi@sjtu.edu.cn of interface more pronounced. Thus, it is essential to reveal the evolution and control of CNT/Al interface to further enhance the performance of composites. During the last decade, much progress has been made on material fabrication and interface research in the field of CNT/Al composite, but much more work still needs to be conducted compared with the $\mathrm{SiC}_{\mathrm{p}} / \mathrm{Al}$ [2] and $\mathrm{C}_{\mathrm{f}} / \mathrm{Al}$ [3] counterparts.

This paper presents an overview of research progress of interface evolution and control in CNT/Al composites, aiming to help exploring the effective approach to take full advantage of the strengthening effect of CNTs via appropriate interface design.

\section{Evolution and Control of CNT/Al Interface}

\subsection{CNT/Al Interface Evolution}

Casting and powder metallurgy (PM) are the major methods for producing CNT/Al composites along with some other novel routes like thermal spray [4] and accumulative roll-bonding [5]. Mechanical interlocking and reaction bonding are the primary bonding types of $\mathrm{CNT} / \mathrm{Al}$ interface. Aluminum carbide $\left(\mathrm{Al}_{4} \mathrm{C}_{3}\right)$ is the main reaction 
product between CNTs and aluminum matrix during consolidation due to the high temperature. The features and evolution of CNT/Al interface in casting and PM differ a lot, which are shown as follows.

\subsubsection{CNT/Al Interface Evolution in Casting}

The poor wettability of non-metallic CNTs in metallic aluminum melt leads to a bad dispersion of CNTs and weak interfacial bonding, which were the main problems in casting CNT/Al composites. Even if the dispersion problem no longer bothers, the high temperature during casting would unavoidably result in the structural damage of CNTs, which can cause massive formation of $\mathrm{Al}_{4} \mathrm{C}_{3}$ at interface. To solve this problem, new casting techniques of low temperature and short time, such as high pressure die casting [6], stir casting [7], and squeeze casting [8], have been developed to produce CNT/Al composites. In high pressure die casting [6], the turbulent melt flow in the die could help the dispersion of CNTs, and the contact time between the melt and CNTs was limited, which could hinder the carbide formation. Different from traditional stir casting, the injection of Ni-P-CNT coated aluminum particles instead of raw CNTs [7] seems to alleviate the problems of poor wettability, structural damage, and agglomeration of CNTs in the melt, which may improve the interface. Even so, the lowest temperature of liquid processing is the melting point of aluminum, which is still harmful to CNTs. To further reduce the processing temperature, semi-solid processing has been developed. But here comes another problem, which is the difficulty in dispersing tangled CNTs in viscous fluid.

The work of casting CNT/Al composites is limited and some has already revealed the shortage of casting techniques. Low temperature and rapid casting combined with reinforcement coating should be a practical way to get finer CNT/ $\mathrm{Al}$ interface. Anyway, the natural disadvantage of casting restricts its development in producing CNT/Al composites.

\subsubsection{CNT/Al Interface Evolution in Powder Metallurgy}

Powder metallurgy (PM) draws great attention in producing CNT/Al composite for its convenience and controllability compared to casting. The preparation of CNT/Al composite powders and the compact consolidation are the main procedures of $\mathrm{PM}$, in which the agglomeration of CNTs and the densification of the compact are the major concerns. Both mechanical and chemical methods turned out to be effective to disperse the CNTs, in which the applied mechanical force or chemical modification helps separating the tangled CNTs. Different sintering techniques and multiple hot working processes have been used to consolidate the compact. Reaction bonding at CNT/Al interface is established during sintering through diffusion, and the sintered compact is further densified through the elimination of pores by plastic processing.

Mechanical alloying (MA) is the easiest way for dispersing CNTs in MMCs. Series of studies on mechanical alloying of CNT/Al composite powders have been done by Morsi and Esawi [9] and Esawi et al. [10]. Their results showed uniform dispersion of CNTs on aluminum powder surface with few agglomerations. Despite the high effectiveness, one primary weakness of mechanical alloying is the unavoidable structural damage of CNTs introduced by the severe high energy impact during ball-milling. Poirier et al.'s [11] study on mechanically milled CNTs/Al mixture indicated that after ball-milling, CNTs became shorter and more broken with a higher $I_{\mathrm{D}} / I_{\mathrm{G}}$ ratio in Raman spectra. However, the interfacial bonding of ball-milled CNT/Al interface is stronger than that achieved by other methods due to the mechanical interlocking. Among all the processing parameters in MA, milling time is a key factor. If the milling time is not long enough, the CNTs will not be separated adequately. However, excessively long-time milling will destroy the CNTs. The damaged CNTs are easier to react with aluminum matrix during sintering, which causes further structural failure of CNTs. So it is necessary to develop new ball-milling techniques for dispersion with lower milling velocity (softer impact on CNTs) and shorter milling time. In this way, the structural integrity and outstanding mechanical property of CNTs can be retained.

Apart from mechanical alloying, some other novel techniques like chemisorption [12] and chemical vapor deposition [13] have also been applied to prepare CNT/Al composite powders. By changing spherical $\mathrm{Al}$ powders into nanoflakes and surface modifying them with a polyvinyl alcohol hydrosol as shown in Fig. 1, Jiang et al. [12] achieved high compatibilities between $\mathrm{Al}$ powders and CNTs, leading to a uniform dispersion of CNTs on aluminum powders using flake powder metallurgy (flake PM). He et al. [13] synthesized uniform-dispersed $\mathrm{CNT}(\mathrm{Ni}) / \mathrm{Al}$ composite powders using CVD method for the first time. Through series of chemical procedures, Ni nanoparticles (catalyst) with a narrow diameter distribution spread evenly on the surfaces of $\mathrm{Al}$ powders followed by in situ synthesis of CNTs through chemical vapor deposition. In general, the dispersion of CNTs is good enough in these methods, but the introduced CNT/Al interface is extremely weak due to the lack of mechanical or thermal driving force. To overcome this weakness, a short-time ballmilling of the as-prepared powders was used [14, 15]. The plastic deformation brought by milling made the CNTs embedded into aluminum powders.

After preparation of composite powders, compact consolidation is another critical procedure in the evolution of CNT/Al interface. Generally speaking, sintering combined with plastic processing is the most frequently used method 


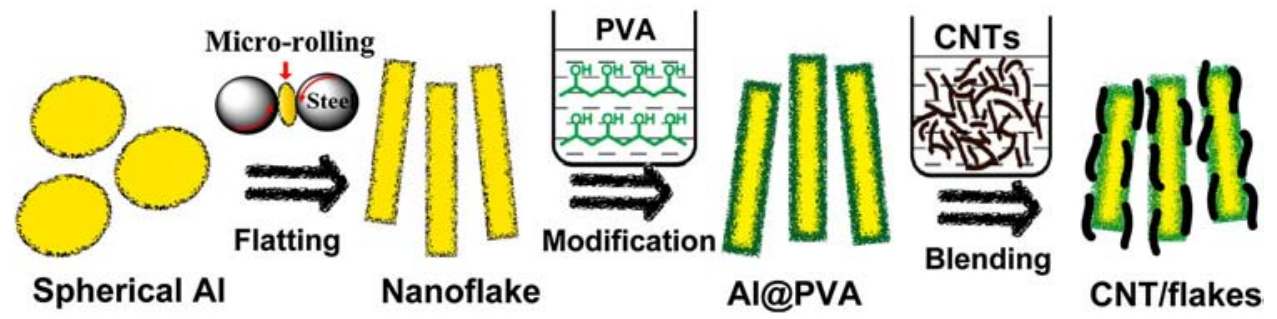

Fig. 1 Schematic of slurry blending by flake PM [12]

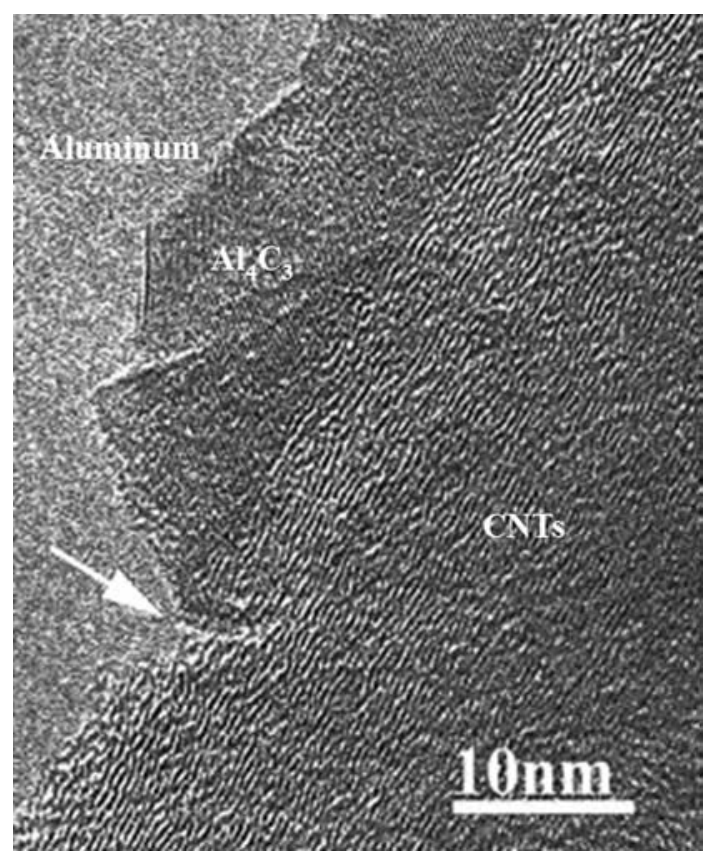

Fig. 2 TEM image of aluminum carbide at CNT/Al interface and notch on CNTs (denoted by white arrow) [19]

for consolidation, while just hot working without sintering is also practicable [16-18]. The primary parameter affecting the consolidation process is temperature, which should be high enough to provide necessary thermal driving force for reaction bonding at interface. Learnt from previous studies, different consolidation routes all share the same concern, which is the appearance of $\mathrm{Al}_{4} \mathrm{C}_{3}$ at interface as shown in Fig. 2 [19]. To the best of present knowledge, rapid sintering with high pressure seems to be a feasible solution. The pressure applied to compact can help reducing the needed sintering temperature, and the short period sintering process can hinder the formation of $\mathrm{Al}_{4} \mathrm{C}_{3}$ kinetically.

By knowing these, spark plasma sintering (SPS) has been developed [20, 21]. Although great interfacial improvement has been made by SPS, one still existing problem is the nonuniform temperature field inside compact compared with traditional heating techniques, which may cause local overheating. Even so, SPS is still a promising sintering method.
After sintering, lower temperature plastic processing, such as extrusion [22] and friction stir processing (FSP) [23, 24], is a good way to further disperse the CNTs and densify the compact as long as the CNT/Al interface is well protected from damage. In general, rapid sintering with further plastic processing is a good combination for compact consolidation, which can constrain the formation of $\mathrm{Al}_{4} \mathrm{C}_{3}$ and establish tight interfacial bonding at the same time.

\subsection{Control of CNT/Al Interface}

Usually, it is difficult to get a strong and ductile CNT/Al interface only by regulating the processing parameters like sintering temperature or pressure. So reinforcement coating as an effective and convenient regulating method has been developed for CNT/Al interface control.

Various coatings such as $\mathrm{NiO}$ [25], $\mathrm{SiC}$ [26], copper [27], molybdenum [28], Ni-P [29], and aluminum [30] have been tried on CNTs. All of these researches indicated a better wettability and stronger interfacial bonding between aluminum matrix and the coated CNTs. The SEM image of Ni-P coated multi-walled CNTs (MWCNTs) showed better wettability and dispersion in aluminum after heat treatment compared with the non-coated ones, as shown in Fig. 3 [29]. Although there is no direct high resolution observation of coated CNT/Al interface yet, the reason of interface improvement can be explained by the electronic bonding theory proposed by Mitra and Mahajan [31], which indicates that the metallic matrix tends to establish tighter bonding with a more metallic phase. In those studies, aluminum matrix contacted directly with the more metallic coating layer instead of non-metallic CNTs, which leads to a finer interface after sintering. In this case, specific metallic coating on the CNT surface should be a more feasible choice according to Ref. [31]. If the metallic coating layer can react with aluminum matrix to form intermetallic interphases, the interfacial property will be much improved. There are two reasons responsible for this. Firstly, it is the good compatibility due to similar electronic bonding of intermetallic interphase and aluminum matrix that leads to high bonding strength. Secondly, different 

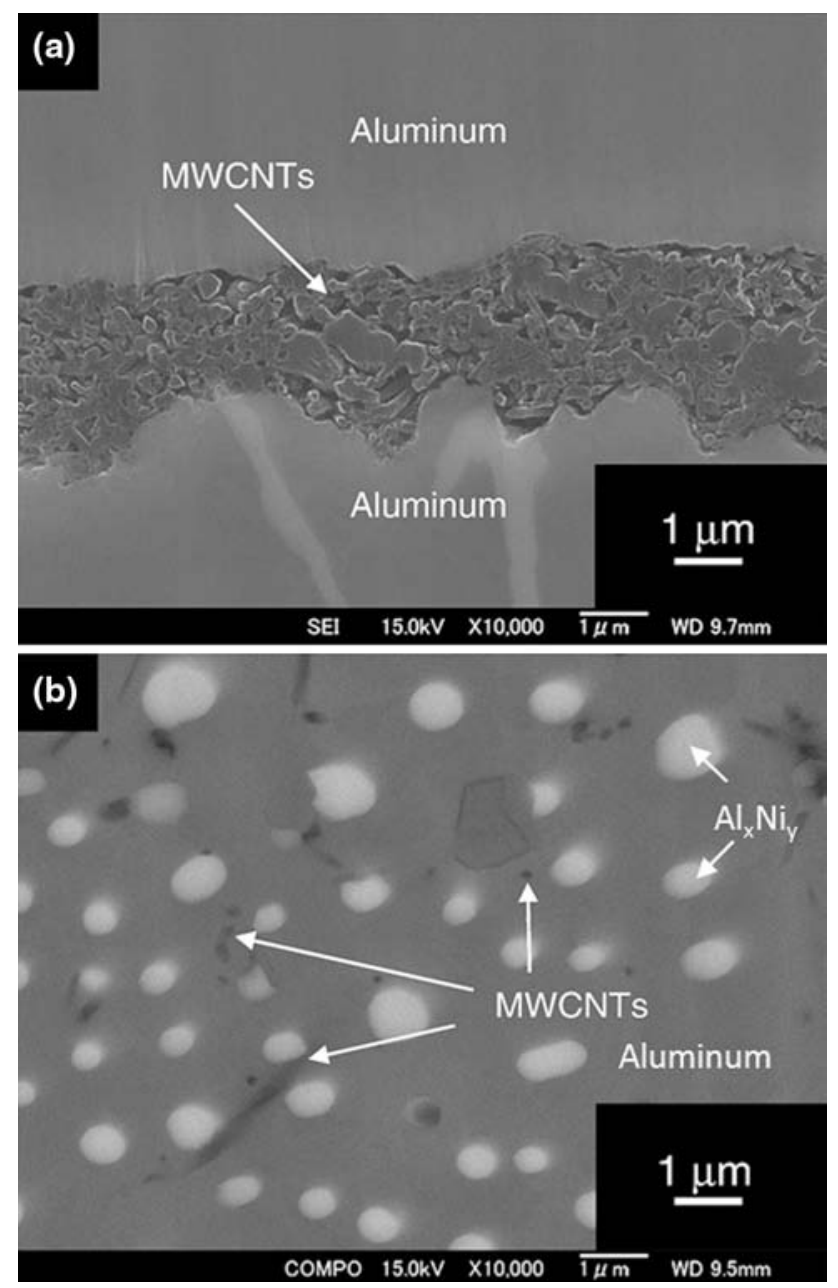

Fig. 3 SEM images showing non-coated MWCNTs (a), Ni-9 at\% P coated CNTs (b) in aluminum after heat treatment [29]

from the brittle $\mathrm{Al}_{4} \mathrm{C}_{3}$, these relatively ductile intermetallic interphases will keep the interface tough and act as a reaction barrier to protect CNTs. So metallic coating layer should be a good selection for a strong and ductile CNT/Al interface and the intermetallic interphases as the reaction product is beneficial for enhanced interfacial properties.

By and large, deeper research of coating is still in demand. Except coating, other interface controlling methods should also be developed in future.

\section{Effects of CNT/Al Interface on Properties}

As a transition region, the large volume fraction of interface plays a significant role in property transfer from aluminum matrix to CNTs. The structure, the interphase property, and the bonding strength of the interface all affect the bulk property of CNT/Al composites. Only by finding out the effects of all these interfacial factors on properties we can enhance the mechanical and functional performance of
CNT/Al composite. The studies of MMCs with nano-sized reinforcements are far from being enough. With few regulating method, the research of interfacial effect is restricted. Present knowledge in the effect of interface is based on the limited experiment data, experience of former scientist, and theoretical inference.

\subsection{Effects of Interface on Mechanical Performance}

$\mathrm{CNT} / \mathrm{Al}$ interface is a significant factor in strengthening. If the applied load cannot be transferred to CNTs, the high tensile strength and elastic modulus of the CNTs will be underutilized. A strong CNT/Al interface is needed for effective load transfer. According to the Coleman's model [32], stronger interface leads to higher composite strength. Besides strength, ductility of CNT/Al interface is also important for mechanical performance. If the interface is strong, but brittle, voids, and cracks may easily form during mechanical processing, which will increase the defect density and weaken the mechanical properties of CNT/Al composites. So a strong and ductile interface can avoid the structural failure of interface under high load and ensure the stability of mechanical performance. In addition, due to the nanometer size of CNT/Al interface, the direct characterization of the interfacial strength is still a big problem. The in situ tensile test under TEM may be a practical way.

In some studies [20,33], the limited formation of $\mathrm{Al}_{4} \mathrm{C}_{3}$ at interface was believed to strengthen the interfacial bonding and enhance the mechanical performance of CNT/ Al composites. However, Li et al. [34] found that the enhancement efficiency of herringbone CNTs in Al matrix composites was lower than that of tubular CNTs, due to the presence of the brittle $\mathrm{Al}_{4} \mathrm{C}_{3}$ intermediate layer. Totally opposite results were given by these authors, but none of them showed sufficient evidence. To the present point of view, the formation of carbide does enhance the wettability and bonding strength, while its brittleness is a great concern for structural application. So it should be well balanced with the advantages and disadvantages of $\mathrm{Al}_{4} \mathrm{C}_{3}$. Besides this, the interfacial strength should not be too high or too weak. The load transfer efficiency will be much lower, if the interface is too weak, while an excessively strong interface may hinder the pull-out behavior of the reinforcement, which will embrittle the $\mathrm{CNT} / \mathrm{Al}$ composite. This point of view has been proved in other discontinuously reinforced metal matrix composites and should also be feasible for CNT/Al interface design.

In consideration of the intrinsic shortage of naturally formed aluminum carbide, it is important to get some metallic coating on the surface of CNTs to form intermetallic interphases instead of the carbide at interface. In that case, both the strength and ductility of CNT/Al interface can be improved. Apart from the theoretical studies, the 
direct test for mechanical properties of interface should be the focus of future work.

\subsection{Effects of Interface on Functional Performance}

Compared with the research of interfacial effects on mechanical performance, little progress has been made in the field of functional performance. It is believed that the physical property and geometry of CNT/Al interphase rather than the interfacial strength greatly affects the functional performance of CNT/Al composite. Lots of related researches in other MMCs systems have proved this.

For thermal properties, very little work has been conducted in CNT/Al composite, and some has reported an improved thermal conductivity in CNT/Al composites with $\mathrm{Al}_{4} \mathrm{C}_{3}$ interphase [35]. However, the specific effect of the interface is still unknown. Due to the large volume fraction of interface, the effect of thermal interfacial resistance is much more dominant. To cut down its effect, interphase of higher thermal conductivity and tighter interfacial bonding is critical.

The research on functional performances of CNT/Al composite just starts off. Further study on effects of interphase properties still needs to be done.

\section{Conclusions and Expectation}

$\mathrm{CNT} / \mathrm{Al}$ composite has been extensively studied during the last decade, and CNT/Al interface plays important but different roles in both mechanical and functional properties. A strong and ductile CNT/Al interface is always desirable for enhanced mechanical performance, while the physical property and geometry of interphase matters more for functional application. The presence of $\mathrm{Al}_{4} \mathrm{C}_{3}$ interphase caused by high temperature reaction is the major concern in CNT/Al interface. Surface coating of CNTs with metallic layer and the formation of intermetallic interphases prove to be an effective method for maintaining the structural integrity of CNTs and improving both the interfacial strength and ductility. With the growing demand in materials of combined mechanical and functional performance, higher requirements are raised for CNT/Al interface design, and further studies still need to be conducted in elaborating interface control and direct characterization of interfacial properties.

\footnotetext{
Acknowledgments This work was financially supported by the National Basic Research Program of China (No. 2012CB619600), the National Natural Science Foundation of China (Nos. 51131004, 51071100, and 51001071), the National High Technology Research and Development Program of China (No. 2012AA030311), and Shanghai Science \& Technology Committee (Nos. 11JC1405500).
}

\section{References}

[1] S.R. Bakshi, D. Lahiri, A. Agarwal, Int. Mater. Rev. 55, 41 (2010)

[2] J.C. Lee, J.P. Ahn, J.H. Shim, Z. Shi, H.I. Lee, Scr. Mater. 41, 895 (1999)

[3] S. Warrier, C. Blue, R. Lin, J. Mater. Sci. 28, 760 (1993)

[4] S.R. Bakshi, V. Singh, S. Seal, A. Agarwal, Surf. Coat. Technol. 203, 1544 (2009)

[5] S. Salimi, H. Izadi, A. Gerlich, J. Mater. Sci. 46, 409 (2011)

[6] Q. Li, C.A. Rottmair, R.F. Singer, Compos. Sci. Technol. 70, $2242(2010)$

[7] B. Abbasipour, B. Niroumand, S.M. Monir Vaghefi, Trans. Nonferrous. Met. Soc. China 20, 1561 (2010)

[8] H. Uozumi, K. Kobayashi, K. Nakanishi, T. Matsunaga, K. Shinozaki, H. Sakamoto, T. Tsukada, C. Masuda, M. Yoshida, Mater. Sci. Eng. A 495, 282 (2008)

[9] K. Morsi, A. Esawi, J. Mater. Sci. 42, 4954 (2007)

[10] A.M.K. Esawi, K. Morsi, A. Sayed, A.A. Gawad, P. Borah, Mater. Sci. Eng. A 508, 167 (2009)

[11] D. Poirier, R. Gauvin, R.A.L. Drew, Compos. A 40, 1482 (2009)

[12] L. Jiang, Z. Li, G. Fan, L. Cao, D. Zhang, Carbon 50, 1993 (2012)

[13] C. He, N. Zhao, C. Shi, X. Du, J. Li, H. Li, Q. Cui, Adv. Mater. 19, 1128 (2007)

[14] X. Yang, E. Liu, C. Shi, C. He, J. Li, N. Zhao, K. Kondoh, J. Alloys Compd. 563, 216 (2013)

[15] H. Wei, Z. Li, D.B. Xiong, Z. Tan, G. Fan, Z. Qin, D. Zhang, Scr. Mater. 75, 30 (2014)

[16] A.M.K. Esawi, M.A. El Borady, Compos. Sci. Technol. 68, 486 (2008)

[17] C. Deng, D. Wang, X. Zhang, A. Li, Mater. Sci. Eng. A 444, 138 (2007)

[18] T. Kuzumaki, K. Miyazawa, H. Ichinose, K. Ito, J. Mater. Res. 13, 2445 (1998)

[19] L. Ci, Z. Ryu, N.Y. Jin-Phillipp, M. Rühle, Acta Mater. 54, 5367 (2006)

[20] H. Kwon, M. Estili, K. Takagi, T. Miyazaki, A. Kawasaki, Carbon 47, 570 (2009)

[21] H. Kwon, D.H. Park, J.F. Silvain, A. Kawasaki, Compos. Sci. Technol. 70, 546 (2010)

[22] J.Z. Liao, M.J. Tan, I. Sridhar, Mater. Des. 31, S96 (2010)

[23] Z.Y.Liu, B.L. Xiao, W.G. Wang, Z.Y. Ma, Carbon 50, 1843 (2012)

[24] Z.Y. Liu, B.L. Xiao, W.G. Wang, Z.Y. Ma, Carbon 69, 264 (2014)

[25] T.H. Kim, M.H. Park, K.W. Song, J.H. Bae, J.W. Lee, C.D. Lee, C.W. Yang, J. Nanosci. Technol. 13, 7685 (2013)

[26] K.P. So, J.C. Jeong, J.G. Park, H.K. Park, Y.H. Choi, D.H. Noh, D.H. Keum, H.Y. Jeong, C. Biswas, C.H. Hong, Y.H. Lee, Compos. Sci. Technol. 74, 6 (2013)

[27] A. Maqbool, M.A. Hussain, F.A. Khalid, N. Bakhsh, A. Hussain, M.H. Kim, Mater. Charact. 86, 39 (2013)

[28] J.H. Nie, C.C. Jia, N. Shi, Y.F. Zhang, Y. Li, X. Jia, Int. J. Min. Met. Mater. 18, 695 (2011)

[29] S. Arai, Y. Suzuki, J. Nakagawa, T. Yamamoto, M. Endo, Surf. Coat. Technol. 212, 207 (2012)

[30] K.P. So, Il H. Lee, D.L. Duong, T.H. Kim, S.C. Lim, K.H. An, Y.H. Lee, Acta. Mater. 59, 3313 (2011)

[31] R. Mitra, Y. Mahajan, Bull Mater. Sci. 18, 405 (1995)

[32] J.N. Coleman, M. Cadek, R. Blake, V. Nicolosi, K.P. Ryan, C. Belton, A. Fonseca, J.B. Nagy, Y.K. Gunko, W.J. Blau, Adv. Func. Mater. 14, 791 (2004)

[33] L. Tham, M. Gupta, L. Cheng, Acta Mater. 49, 3243 (2001)

[34] H. Li, J. Kang, C. He, N. Zhao, C. Liang, B. Li, Mater. Sci. Eng. A 577, 120 (2013)

[35] P.W. Ruch, O. Beffort, S. Kleiner, L. Weber, P.J. Uggowitzer, Compos. Sci. Technol. 66, 2677 (2006) 